\title{
El marco jurídico argentino del ordenamiento territorial: ¿propicia un desarrollo sostenible?
}

\section{LEONOR SELENA GIMELFARB}

Instituto de Ambiente de Montaña y Regiones Áridas, Universidad Nacional de Chilecito, Argentina

Igimelfarb@undec.edu.ar

\section{RESUMEN}

Este trabajo indaga cómo se instrumenta jurídicamente la consecución del desarrollo sostenible mediante el ordenamiento territorial. Su objetivo fue contribuir al conocimiento del marco jurídico argentino del ordenamiento territorial, examinando si propicia un desarrollo sostenible. Se realizó un estudio de caso, relevando y analizando las 3I leyes que conforman este marco jurídico. Se elaboró un marco conceptual que profundiza en la vinculación entre ordenamiento territorial y desarrollo sostenible, a partir del cual se formularon diez dimensiones de análisis y 27 indicadores. Su aplicación a las leyes relevadas permitió identificar normas que propician un desarrollo sostenible. El análisis mostró que el marco jurídico vigente contiene un número reducido de tales normas y no pueden considerarse un instrumento adecuado de desarrollo sostenible. El trabajo concluye con la recomendación de desarrollar los lineamientos sobre ordenamiento ambiental del territorio, establecidos por la Ley General del Ambiente, mediante una ley sectorial de presupuestos mínimos.

PALABRAS CLAVE: ordenamiento ambiental del territorio; derecho ambiental; desarrollo territorial sostenible. 


\section{ABSTRACT}

THE ARGENTINIAN LEGAL FRAMEWORK FOR SPATIAL PLANNING: DOES IT FOSTER SUSTAINABLE DEVELOPMENT?

This paper investigates the legal implementation of sustainable development through spatial planning. Its aim was to contribute to the knowledge of the Argentinian legal framework for spatial planning, by examining whether it fosters such development. We carried out a case study, compiling and analyzing the $3 \mathrm{I}$ laws that make up this legal framework. We developed a conceptual framework that delves into the link between spatial planning and sustainable development. Based on this conceptual framework, we formulated ten dimensions of analysis and 27 indicators. We applied them to the compiled laws, thus identifying norms that foster sustainable development. The analysis showed that the current legal framework contains a small number of such norms and cannot be considered an adequate instrument for sustainable development. The paper concludes that the guidelines on environmental spatial planning established by the General Environmental Law should be developed with the drafting of a specific law.

KEYWORDS: environmental spatial planning; environmental law; sustainable territorial development. 
RESUMO

O QUADRO JURÍDICO ARGENTINO DA ORDENAMENTO DO TERRITÓRIO: PROMOVE DESENVOLVIMENTO SUSTENTÁVEL?

Neste trabalho indaga-se como é instrumentada juridicamente a consecução do desenvolvimento sustentável mediante o ordenamento do território. Seu objetivo foi contribuir ao conhecimento do quadro jurídico argentino do ordenamento do território, visando se propicia um desenvolvimento sustentável. Foi realizado um estudo de caso, revelando e analisando as 3I leis que conformam esse enquadramento legal. Também, foi elaborado um arcabouço conceitual focalizando na vinculação entre ordenamento do território e desenvolvimento sustentável, a partir do qual formula-se dez dimensóes do analise e 27 indicadores. Sua aplicação às leis relevadas permitiu identificar normativas para propiciar esse desenvolvimento. $\mathrm{O}$ analise mostrou que o quadro jurídico atual contém um número pequeno de tais normas e não podem se considerar um instrumento adequado para o desenvolvimento sustentável. O trabalho conclui com a recomendaçáo de desenvolver os lineamentos sobre ordenamento ambiental do território, estabelecidos pela Lei Geral do Meio Ambiente, a traves de uma lei setorial de orçamentos mínimos.

PALAVRAS-CHAVE: ordenamento ambiental do território; direito ambiental; desenvolvimento territorial sustentável. 


\section{Introducción}

Este trabajo indaga cómo se instrumenta jurídicamente la consecución del desarrollo sostenible mediante el ordenamiento territorial. Este tema surge a partir de una afirmación frecuente en la bibliografía especializada: que el ordenamiento territorial constituye un instrumento para el desarrollo sostenible (Gudiño, 20I6; Mahaim, 20I4; Massiris, 20I2; Pastorino, 2009; Psathakis et al., 2010; Vargas, 2002; Walsh, 2009). Algunos autores expresan esta idea con cierto énfasis, alegando que el ordenamiento territorial sería la estrategia más indicada para alcanzar tal desarrollo: "Debido al modelo socioproductivo dominante, el único modo de avanzar hacia territorios más sostenibles (...) es tener presente la necesidad de planificar adecuadamente el desarrollo territorial", afirman, por ejemplo, Ferrandis Martínez y Noguera Tur (2016:754).

A la vez, la ambigüedad que parece caracterizar el concepto de desarrollo sostenible (Bermejo Gómez de Segura, 2014; Elizalde, 2009; Gudynas, 20I0; Guimarães, 1994; Lélé, 1991; Massiris, 20I2) complica su aplicación a políticas territoriales y hace necesario avanzar en la definición de criterios para tal fin (Ferrandis Martínez y Noguera Tur, 2016). A partir de una lectura analítica de autores de distintos países que se dedicaron a pensar en profundidad la vinculación entre ordenamiento territorial y desarrollo sostenible, creemos posible identificar tales criterios.

Por otra parte, como política pública, el ordenamiento territorial requiere de instrumentos para generar los efectos deseados; en particular, un marco regulatorio propio, adecuado a su naturaleza, que oriente el proceso de organización territorial (Gudiño, 2009). El marco legal y reglamentario constituye un importante recurso de las políticas públicas, que organiza tanto su contenido -definición de objetivos y conducta de los grupos-objetivo-, como la selección de los otros recursos -organizacionales, procedimentales o financieros- (Subirats, Knoepfel, Larrue y Varone, 2008). Además, la implementación del ordenamiento territorial genera fuertes contradicciones entre los intereses de los actores sociales; ante los conflictos que surgen entre opositores a sus fines y los sectores que aspiran a mejorar su calidad de vida, la regulación y el control se vuelven imprescindibles (Salas Bourgoin y Sulbarán Zambrano, 20II).

En este contexto, la existencia de marcos jurídicos adecuados favorece la implementación de políticas públicas que fomenten un desarrollo 
sostenible. Si la legislación vigente contiene normas que propician tal desarrollo, parece factible que el ordenamiento territorial que se realice, en la medida que se implemente conforme a estas normas, contribuya a este fin. Mientras que, si la legislación carece de tales normas, es poco probable que constituya un instrumento de desarrollo sostenible.

Nos interesó entonces, conocer la conformación del marco jurídico del ordenamiento territorial -el conjunto de normas jurídicas que lo regulay verificar si incorpora normas pertinentes. Así, el objetivo del trabajo fue examinar si el marco jurídico del ordenamiento territorial vigente a nivel nacional en Argentina propicia un desarrollo sostenibler. Esta cuestión puede abordarse desde diversas perspectivas teóricas, ya que el desarrollo es un fenómeno multidimensional (Alburquerque y Pérez Rozzi, 20I3) y que su comprensión está mediatizada por posturas ideológicas (Elizalde, 1992; Massiris, 2012), las cuales se ven reflejadas en la legislación. Atento a que el ordenamiento territorial es considerado un proceso (Massiris, 20I3), en este trabajo se eligió una mirada procedimental.

Realizamos un estudio de caso, relevando y analizando las leyes vigentes al $\mathrm{I}^{\circ}$ de septiembre de 20I9. Se formularon dimensiones de análisis e indicadores a partir de un marco conceptual que profundiza en la vinculación entre ordenamiento territorial y desarrollo sostenible, y su recepción por el derecho. Debido a su carácter novedoso, que constituye uno de los aportes del presente trabajo, presentaremos este marco conceptual en el próximo apartado.

1 Como primera aproximación al tema, el trabajo se centra en el análisis del marco jurídico (el derecho escrito) y sus efectos potenciales. Cuestiones vinculadas a la implementación de este marco jurídico, al cumplimiento de sus normas (la adecuación del comportamiento de los destinatarios a las prescripciones) y a la aplicación por parte de los tribunales, así como la evaluación de su eficacia (en cuanto logro de los fines perseguidos), es decir, cuestiones referidas al derecho en acción, quedan para investigaciones ulteriores. 


\section{El ordenamiento territorial como instrumento para un desarrollo sostenible: la contribución de la legislación}

La vinculación entre ordenamiento territorial y desarrollo sostenible se remonta a la Carta Europea de Ordenación del Territorio de 1983. Desde entonces, fue tomando protagonismo en los documentos oficiales la expresión "desarrollo territorial sostenible", expresión que se convirtió, a comienzos del siglo XxI, en un principio rector de la planificación territorial occidental (Elorrieta, Olcina y Sánchez, 2016).

En América Latina, el ordenamiento territorial es una actividad relativamente nueva (Panizza y García Collazo, 20I4). Está condicionada por el concepto de desarrollo imperante, de modo que el concepto ha ido evolucionando y es sujeto a diversas interpretaciones (Gudiño, 2009; Massiris, 2005). Esta diversidad conceptual se manifiesta en diferentes enfoques, objetivos y formas de gestión (Massiris, 2005).

Las diversas conceptualizaciones comparten la idea de que el ordenamiento territorial es una política pública que busca regular u organizar el uso, la ocupación y la transformación del territorio en pos de su aprovechamiento óptimo. Tal aprovechamiento implica realizar un ordenamiento acorde con las potencialidades y limitaciones del territorio, las expectativas y aspiraciones de la población, y los objetivos de desarrollo; orientado al uso racional de los recursos naturales, así como basado en patrones adecuados de distribución de asentamientos y de actividades económicas. Estos fines se concretan mediante un sistema integrado de directrices, programas, planes y actuaciones de las instituciones del Estado, que buscan compatibilizar los objetivos de políticas sectoriales en los distintos niveles territoriales (García Collazo y Panizza, 20I4; Gudiño, 2009; Massiris, 2005).

Comparando las definiciones establecidas en diez normas o políticas vigentes en América Latina, Massiris (2013:77) formuló el siguiente concepto regional de ordenamiento territorial:

Política de estado y proceso político-técnico-administrativo, concertado y prospectivo, con el que se pretende configurar, en el largo plazo, una organización del uso y la ocupación del territorio y orientar su transformación, de acuerdo con principios de sostenibilidad ecológica, equidad territorial, respeto a la diversidad cultural y conciliación del desarrollo económico, social y ambiental. Todo ello, en la búsqueda de mejores condiciones de vida para todos los habitantes del territorio. 
Este concepto de ordenamiento territorial se enmarca en la idea de desarrollo sostenible, idea que se popularizó a partir de 1987 con la publicación del Informe Brundtland. Según sus autores, tal desarrollo permite satisfacer nuestras necesidades sin comprometer la capacidad de las generaciones futuras para satisfacer sus propias necesidades (Comisión Mundial para el Medio Ambiente y el Desarrollo, 1987)². El marco conceptual que elaboró desde entonces la Organización de las Naciones Unidas para orientar a los gobiernos en la formulación de políticas nacionales en tal sentido, evolucionó con el paso del tiempo (Bermejo Gómez de Segura, 20I4). En la actualidad, en el marco de la Agenda 2030 para el Desarrollo Sostenible, se afirma la necesidad de armonizar el crecimiento económico, la inclusión social y la protección del ambiente (Asamblea General de las Naciones Unidas, 2015).

Sin embargo, la posibilidad de tal armonización es debatida. Si el crecimiento económico suele considerarse imprescindible para el desarrollo (Máttar y Perrotti, 20I4), diversos autores han cuestionado el modelo de desarrollo basado en el crecimiento, por los graves problemas socioambientales que le atribuyen (Brañes, 200I; Norgaard, 1994), y advertido la necesidad de su rediseño (Elizalde, 1992; Gudynas, 2010; Guimarães, 2002; Pastorino, 2009). Entre los enfoques críticos que se han elaborado, pueden reconocerse alternativas que admiten las bases conceptuales del desarrollo y otras que buscan generar marcos conceptuales distintos (Gudynas, 20II). La perspectiva adoptada en el presente trabajo acepta el concepto de desarrollo, aunque hace hincapié en la necesidad de conservar un stock natural crítico, lo cual implica mantener el agregado total del capital natural, esencialmente en sus niveles actuales ${ }^{3}$.

La consecución del desarrollo sostenible, más allá de cómo se conciba este, demanda un marco regulatorio apropiado, que impida los modelos de desarrollo destructivo (Brañes, 200I), e integre la protección del ambiente

2 Esta conceptualización del desarrollo sostenible es la que inspiró el constituyente argentino: "Todos los habitantes gozan del derecho a un ambiente sano, equilibrado, apto para el desarrollo humano y para que las actividades productivas satisfagan las necesidades presentes sin comprometer las de las generaciones futuras" (Constitución de la Nación Argentina, 1994, art. 41). Es interesante notar que esta disposición incorpora, asimismo, el concepto de "desarrollo humano", concepto elaborado a partir de 1990 por el Programa de las Naciones Unidas para el Desarrollo (López Alfonsín, 2012).

3 Esta postura se corresponde con la corriente de sostenibilidad "fuerte", en la clasificación de Gudynas (2010:47). 
y el desarrollo. No es suficiente sancionar leyes ambientales por un lado y leyes de desarrollo por el otro, sino que la legislación debe contemplar ambas problemáticas de manera integrada (Organización de las Naciones Unida, 1992). Es menester que el sistema legal se vuelva compatible con las leyes naturales, asegurando la inclusión de consideraciones ambientales en todas las decisiones (Lorenzetti, 2008; Pastorino, 2009).

A pesar del reconocimiento de la importancia de la protección del ambiente para el desarrollo sostenible (Declaración de Río, 1992), la comunidad internacional no ha logrado frenar su deterioro y la resultante pérdida de recursos naturales vitales condena a gran parte de la población mundial a vivir en situación de pobreza (Declaración de Johannesburgo, 2002). La creciente degradación del ambiente y sus consecuencias para las personas, las economías y la seguridad de las naciones, son motivos de preocupación (Programa de las Naciones Unidas para el Medio Ambiente, 20I8). La implementación de adecuadas estrategias para lograr una mayor sostenibilidad del desarrollo aparece cada vez más urgente. No obstante, los distintos países que conforman la comunidad internacional encuentran dificultades, en parte debido a la imposibilidad de definir el desarrollo sostenible de manera operativa (Norgaard, 1994).

Sin embargo, existe consenso en torno a que se ha vuelto imprescindible equilibrar el nivel de consumo de recursos naturales con las condiciones naturales (Gudynas, 20I0; Massiris, 2012), haciendo de aquellos un uso eficiente y mucho más moderado de lo que estamos acostumbrado como sociedad (Riechmann, 20I2). La mesura en el consumo de los recursos se ha convertido en un requisito ineludible si queremos que las generaciones futuras puedan gozar de las mismas posibilidades que la actual (Burgess, 2003; Elizalde, 2009).

En consecuencia, para que el desarrollo sea sostenible, debe mantenerse este consumo dentro de determinados parámetros: los recursos naturales renovables no se deben extraer más allá de la cosecha; respecto de los no renovables, se debe garantizar su adecuada sustitución y limitar su apropiación cuando no tienen sustituto (Gudynas, 20IO; Guimarães, 2002). Toda utilización de un recurso no renovable sin sustituto, como el suelo, constituye un consumo de capital (natural) y genera un daño irreversible. Siendo intrínsecamente insostenible, tal consumo debe restringirse, buscando diversas formas de minimizarlo (Mahaim, 20I4; Riechmann, 20I2).

A la necesidad de frenar el consumo de suelo, en cuanto recurso 
natural no renovable, se suman los inconvenientes que ocasiona la urbanización de nuevas superficies: reducción de los hábitats naturales, los suelos agrícolas y los recursos hídricos; así como aumento de la contaminación, el consumo energético, la emisión de óxido de carbono y la generación de desechos (Burgess, 2003). Muchos recursos naturales y los ecosistemas que los producen no son ilimitados (Riechmann, 2005), y la capacidad de absorción de los ecosistemas urbanos tampoco; por lo que se debe conservar los recursos y minimizar sus usos injustificados. En este contexto, se ha vuelto imprescindible aumentar la densidad urbana, buscando generar ciudades compactas (Burgess, 2003). La conveniencia de regular el consumo de suelo pone de manifiesto la vinculación existente entre ordenamiento territorial y desarrollo sostenible.

La identificación del ordenamiento territorial como instrumento para lograr el desarrollo sostenible existió desde los albores del concepto: el Programa 2I, el plan de acción adoptado en la Conferencia de Río, plantea que tal desarrollo puede lograrse mediante un abordaje integrado de planificación y gestión del territorio (Organización de las Naciones Unida, 1992).

Efectivamente, el ordenamiento territorial puede fortalecer diversos componentes del desarrollo sostenible, tales como: la lucha contra la pobreza y el fomento de la equidad, mediante la provisión de viviendas; la productividad, mediante un manejo integrado de los territorios; la calidad ambiental, mediante el ordenamiento de las actividades en el espacio urbano; así como la prevención de desastres naturales, mediante la planificación de los asentamientos humanos y su localización en zonas seguras (Montes Lira, 200I). En definitiva, ordenar un territorio es identificar sus potencialidades, limitaciones y riesgos, con el objeto de distribuir los asentamientos y las actividades de tal modo que se pueda garantizar la vida y el desarrollo en condiciones de sostenibilidad (Gómez Orea y Gómez Villarino, 2013; Massiris, 2012; Vargas, 2002). En tal sentido constituye el ordenamiento territorial un instrumento de planificación del desarrollo territorial sostenible (Massiris, 2012:79) 4

El desarrollo integral de los sistemas territoriales se logra impulsando

4 Si bien la planificación para el desarrollo perdió protagonismo en el ejercicio de las políticas públicas hacia fines del siglo xx, debido, en parte, a sus modestos resultados, se vio revalorizada en años recientes. Resurge en la actualidad como valiosa herramienta de coordinación del proceso hacia el desarrollo deseado (Máttar y Perrotti, 2014). 
la elaboración de modelos territoriales sostenibles, por medio de políticas de intervención planificada para la transformación de los territorios. Para lograr sus fines, estas políticas deben satisfacer diversos criterios, entre otros: considerar el territorio como un elemento esencial para el desarrollo, teniendo en cuenta su naturaleza sistémica y compleja; otorgar la prioridad a la planificación territorial; así como considerar los recursos territoriales endógenos y promover actividades acordes con las características y aspiraciones de su población (Ferrandis Martínez y Noguera Tur, 2016). Estas políticas requieren realizar un diagnóstico integral del territorio (Rodríguez y Reyes, 2008) y localizar los usos del suelo en función de criterios ambientales, sociales y económicos (Mahaim, 20I4).

Sistematizando los aportes de los autores consultados, es posible identificar diez requisitos que debe satisfacer el ordenamiento territorial para contribuir al desarrollo sostenible:

1. Carácter integral: el ordenamiento territorial es obligatorio en todo el territorio, no se realizan ordenamientos parciales.

2. Conocimiento de las potencialidades, limitaciones, problemas y riesgos del territorio a ordenar: relevamiento completo de sus características, mediante un diagnóstico integrado de los diferentes subsistemas que lo componen, y realización de una evaluación ambiental, que permita entender la interacción entre la ocupación del territorio y los diversos componentes del ambiente.

3. Elaboración de modelos territoriales sostenibles: los objetivos estratégicos del ordenamiento territorial están orientados a un proyecto territorial que responde al desarrollo sostenible, los objetivos operativos reflejan las tres dimensiones de este y el ordenamiento concilia los distintos objetivos.

4. Minimización del consumo de suelo mediante la determinación de la cantidad máxima de suelo disponible para urbanización, en función de la sostenibilidad ecológica y de las zonas de riesgos.

5. Localización de los usos del suelo por medio de una planificación integral, que contemple todos los usos e incorpore consideraciones ambientales, sociales y económicas. Con este fin, se ejerce una coordinación intersectorial e interterritorial y se realiza una ponderación de los intereses presentes. 
6. Planificación y control de los asentamientos humanos de modo de evitar la dispersión y la fragmentación urbana: los asentamientos se distribuyen en función de las potencialidades, limitaciones y riesgos específicos identificados; se localizan en zonas seguras, con acceso a infraestructura básica y calidad ambiental.

7. Provisión de viviendas, en particular para los sectores de menores recursos: se construyen viviendas apropiadas, en cantidad suficiente y adecuadamente localizadas, en cercanía de los puestos de trabajo y con accesibilidad a medios de transporte público.

8. Selección de las actividades a llevar a cabo en el territorio para soportar el desarrollo, con enfoque estratégico y endógeno, y en función del diagnóstico territorial realizado. Se proveen suficientes terrenos adecuadamente localizados y dotados para la realización de estas actividades y se regula su comportamiento de modo de minimizar su impacto ambiental.

9. Integración de las cuestiones ambientales en la formulación de los planes de ordenamiento, identificación de los impactos ambientales que estos generarán y definición de las medidas necesarias para su prevención y minimización, mediante procedimientos de evaluación ambiental estratégica.

10. Promoción de una participación social informada y efectiva en todas las fases del ordenamiento territorial (diagnóstico, planificación, gestión, control y seguimiento), mediante mecanismos adecuados.

En función de estos requisitos, se formularon diez dimensiones para el análisis del marco jurídico del ordenamiento territorial: I. carácter del ordenamiento territorial; 2. diagnóstico territorial; 3. modelo territorial deseado; 4. consumo de suelo; 5 . localización de los usos del suelo; 6. asentamientos humanos; 7. provisión de viviendas; 8 . actividades a realizar en el territorio; 9. evaluación de los planes de ordenamiento; Io. participación ciudadana. Para cada dimensión se formularon indicadores que puedan ser aplicados a normas jurídicas (cuadro I). 
Cuadro 1. Dimensiones e indicadores para el análisis de los marcos jurídicos del ordenamiento territorial (OT) en función del desarrollo sostenible

\begin{tabular}{|c|c|}
\hline $\begin{array}{l}\text { Dimensiones } \\
\text { de análisis }\end{array}$ & Indicadores \\
\hline $\begin{array}{l}\text { 1. Carácter del } \\
\text { ordenamiento } \\
\text { territorial }\end{array}$ & $\begin{array}{l}\text { a. Existencia en los marcos jurídicos vigentes del ordenamiento } \\
\text { territorial (OT) de prescripciones relativas al uso, la ocupación y } \\
\text { la transformación de todo el territorio nacional. }\end{array}$ \\
\hline & $\begin{array}{l}\text { b. Existencia en los marcos jurídicos vigentes del OT de prescrip- } \\
\text { ciones relativas a la realización de un diagnóstico territorial de } \\
\text { carácter integral, que incluya variables ambientales, sociales y } \\
\text { económicas. } \\
\text { c. Existencia en los marcos jurídicos vigentes del OT de prescrip- } \\
\text { ciones relativas a la realización de una evaluación ambiental del } \\
\text { territorio. }\end{array}$ \\
\hline $\begin{array}{l}\text { 3. Modelo territo- } \\
\text { rial deseado }\end{array}$ & $\begin{array}{l}\text { d. Existencia en los marcos jurídicos vigentes del OT de prescrip- } \\
\text { ciones referidas a la utilización de metodologías (como el análisis } \\
\text { prospectivo del territorio) para la construcción de modelos } \\
\text { territoriales. } \\
\text { e. Existencia en los marcos jurídicos vigentes del OT de objetivos } \\
\text { estratégicos formulados en términos de calidad de vida, prevención } \\
\text { de desastres, preservación de los espacios naturales, minimización } \\
\text { del consumo de suelo y/o urbanización en el medio construido. } \\
\text { f. Existencia en los marcos jurídicos vigentes del OT de linea- } \\
\text { mientos para que los objetivos operativos del OT incluyan aspec- } \\
\text { tos ambientales, sociales y económicos. } \\
\text { g. Existencia en los marcos jurídicos vigentes del OT de meca- } \\
\text { nismos de conciliación de los objetivos de las distintas políticas } \\
\text { públicas que inciden en el territorio. }\end{array}$ \\
\hline $\begin{array}{l}\text { 4. Consumo de } \\
\text { suelo }\end{array}$ & $\begin{array}{l}\text { h. Existencia en los marcos jurídicos vigentes del OT de delimi- } \\
\text { taciones de zonas de protección, de cultivo y de riesgo, y de la } \\
\text { prohibición de urbanizarlas. } \\
\text { i. Existencia en los marcos jurídicos vigentes del OT de meca- } \\
\text { nismos de control del crecimiento urbano, tales como límites } \\
\text { cuantitativos al consumo de suelo. } \\
\text { j. Existencia en los marcos jurídicos vigentes del OT de un pro- } \\
\text { cedimiento para la ponderación de los intereses vinculados a la } \\
\text { clasificación como urbanizables de nuevos terrenos. }\end{array}$ \\
\hline $\begin{array}{l}\text { 5. Localización } \\
\text { de los usos del } \\
\text { suelo }\end{array}$ & $\begin{array}{l}\text { k. Existencia en los marcos jurídicos vigentes del OT de la } \\
\text { prescripción de elaborar la planificación territorial en función del } \\
\text { diagnóstico realizado, las potencialidades, limitaciones, proble- } \\
\text { mas y riesgos del territorio y/o criterios ambientales, sociales y } \\
\text { económicos. } \\
\text { l. Existencia en los marcos jurídicos vigentes del OT de la prescrip- } \\
\text { ción de cumplir la legislación ambiental. } \\
\text { m. Existencia en los marcos jurídicos vigentes del OT de mecanis- } \\
\text { mos para armonizar los intereses del mercado y de la sociedad. } \\
\text { n. Existencia en los marcos jurídicos vigentes del OT de mecanis- } \\
\text { mos de coordinación administrativa. }\end{array}$ \\
\hline
\end{tabular}




\begin{tabular}{l|l}
\hline & $\begin{array}{l}\text { O. Existencia en los marcos jurídicos vigentes del OT de pres- } \\
\text { cripciones orientadas a evitar la dispersión y la fragmentación } \\
\text { urbana. } \\
\text { p. Existencia en los marcos jurídicos vigentes del OT de pres- } \\
\text { cripciones que garanticen la localización de los asentamientos } \\
\text { humanos en zonas seguras. } \\
\text { q. Existencia en los marcos jurídicos vigentes del OT de pres- } \\
\text { cripciones relativas a la calidad ambiental de los asentamientos } \\
\text { humanos } \\
\text { humanos. } \\
\text { r. Existencia en los marcos jurídicos vigentes de prescripciones } \\
\text { relativas a la accesibilidad en transporte público. }\end{array}$ \\
\hline 7. Provisión de & $\begin{array}{l}\text { s. Existencia en los marcos jurídicos vigentes del OT de prescrip- } \\
\text { ciones relativas a la provisión de viviendas en cercanías de los } \\
\text { puestos de trabajo. } \\
\text { t. Existencia en los marcos jurídicos vigentes del OT de prescrip- } \\
\text { ciones relativas a la provisión de viviendas para los sectores de } \\
\text { menores recursos. }\end{array}$ \\
\hline 8. Actividades & $\begin{array}{l}\text { u. Existencia en los marcos jurídicos vigentes del OT de mecanis- } \\
\text { mos para la selección de las actividades a realizar en el territorio. } \\
\text { v. Existencia en los marcos jurídicos vigentes del OT de la } \\
\text { prescripción de coordinar las actividades que son incompatibles, } \\
\text { concurrentes, interdependientes o complementarias. } \\
\text { w. Existencia en los marcos jurídicos vigentes del OT de la pres- } \\
\text { cripción de destinar para las actividades productivas terrenos } \\
\text { con acceso a infraestructura. } \\
\text { w. Existencia en los marcos jurídicos vigentes de normas que } \\
\text { regulen el comportamiento de las actividades. }\end{array}$ \\
\hline ciudadana & $\begin{array}{l}\text { y. Existencia en los marcos jurídicos vigentes del OT de la pres- } \\
\text { cripción de realizar una evaluación ambiental estratégica de los } \\
\text { planes de ordenamiento territorial previamente a su aprobación. }\end{array}$ \\
\hline ordenamiento & $\begin{array}{l}\text { z. Existencia en los marcos jurídicos vigentes del OT de mecanis- } \\
\text { mos de participación ciudadana. } \\
\text { aa. Existencia en los marcos jurídicos vigentes del OT de la } \\
\text { prescripción de la participación ciudadana en todas las fases del } \\
\text { ordenamiento territorial. }\end{array}$ \\
\hline &
\end{tabular}

Fuente: elaboración propia a partir de Ferrandis Martínez y Noguera Tur (2016); Gómez Orea (2013); Mahaim (2014); Massiris (2012); Pastorino (2009); Rodríguez y Reyes (2008); Vargas (2002)

En el Cuadro I se detallan los 27 indicadores que permitirán analizar el marco jurídico del ordenamiento territorial en cuanto a si propicia un desarrollo sostenible. En las próximas secciones, identificaremos las leyes que conforman dicho marco jurídico y analizaremos su idoneidad para tal desarrollo, aplicando los indicadores. 


\section{Conformación del marco jurídico del ordenamiento territorial vigente a nivel nacional}

Por marco jurídico entendemos el conjunto de leyes y disposiciones que regulan determinada cuestión o materia. Argentina no cuenta con una ley nacional de ordenamiento territorial, sino que diversas leyes dan soporte a las acciones que este involucra a nivel nacional. Partiendo del relevamiento realizado por García Collazo y Panizza (20I4), que abarca 20 leyes nacionales, lo completamos en función de una consulta realizada en el Sistema Argentino de Información Jurídica. Ingresando en el buscador en línea las palabras clave "ordenamiento territorial", "planificación territorial" y "uso del suelo", encontramos ir leyes más, llegando a un total de 3I leyes ${ }^{5}$. Cabe señalar que ninguna contiene la expresión ordenamiento

5 Ley 12.103 de 1934 Dirección de Parques Nacionales. Creación; Ley 12.665 de 1940 Comisión Nacional de Monumentos, de Lugares y de Bienes Históricos. Creación. Modificatoria Ley 27.103 de 2014 Monumentos y Lugares Históricos; Ley 13.246 de 1948 Arrendamientos rurales y aparcerías; Ley 13.273 de 1948 Defensa de la Riqueza Forestal; Ley 18.575 de 1970 Promoción para el desarrollo de zonas de fronteras; Ley 21.499 de 1977 Régimen de expropiaciones, por razones de utilidad pública, mediante el pago de una justa indemnización; Ley 21.900 de 1978 Adjudicación de tierras fiscales en zonas de frontera; Ley 22.351 de 1980 Administración de Parques Nacionales; Ley 22.428 de 1981 de Fomento de Conservación de Suelos; Ley 24.051 de 1991 Régimen de Desechos Peligrosos; Ley 24.071 de 1992 Aprobación del Convenio Núm. 169 de la OIT sobre Pueblos Indígenas y Tribales en Países Independientes; Ley 25.612 de 2002 Gestión integral de residuos de origen industrial y de actividades de servicio; Ley 25.670 de 2002 Presupuestos mínimos para la gestión y eliminación de los PCBs; Ley 25.675 de 2002 Política Ambiental Nacional (Ley General del Ambiente); Ley 25.688 de 2003 Régimen de Gestión Ambiental de Aguas; Ley 25.743 de 2003 Protección del Patrimonio Arqueológico y Paleontológico; Ley 25.831 de 2004 Régimen de libre acceso a la Información Pública Ambiental; Ley 25.916 de 2004 de Gestión integral de residuos domiciliarios; Ley 26.093 de 2006 Régimen de Regulación y Promoción para la Producción y uso sustentables de Biocombustibles; Ley 26.160 de 2006 Declaración de emergencia en materia de posesión y propiedad de las tierras de las comunidades indígenas originarias del país; Ley 26.168 de 2006 Cuenca Matanza Riachuelo; Ley 26.209 de 2006 Normas aplicables a los catastros territoriales de las distintas jurisdicciones del país (Ley Nacional de Catastro); Ley 26.331 de 2007 Presupuestos mínimos de protección ambiental de los bosques nativos; Ley 26.562 de 2009 Presupuestos mínimos para el control de actividades de quema; Ley 26.639 de 2010 Régimen de presupuestos mínimos de protección ambiental para la preservación de los glaciares y del ambiente periglacial; Ley 26.737 de 2011 Régimen de protección al dominio nacional sobre la propiedad, posesión o tenencia de las tierras rurales; Ley 26.776 de 2012 Definición como política de Estado de la integración física del territorio continental con su territorio insular de la provincia de Tierra del Fuego, Antártida e islas del Atlántico Sur; Ley 26.815 de 2013 Manejo del Fuego; Ley 26.994 de 2014 Código Civil y Comercial de la Nación; Ley 27.231 de 2016 Acuicultura; y Ley 27.324 de 2016 Promoción del desarrollo sustentable de las actividades turísticas de los pueblos rurales. 
territorial en su denominación. No obstante, se las considera vinculadas al ordenamiento territorial porque contienen disposiciones que, directa o indirectamente, inciden en la organización del territorio y deben ser tenidas en cuenta en los procesos de ordenamiento.

Un análisis del articulado de estas leyes revela que, en su mayoría, no tienen por objeto la regulación del uso, la ocupación y la transformación del territorio: sus objetos atañen a la regulación de actividades productivas, a la propiedad y posesión de tierras, a la protección de sistemas naturales y a áreas protegidas. En definitiva, cinco leyes se refieren explícitamente al ordenamiento territorial, con diversos alcances. Cuatro de ellas establecen ordenamientos parciales, ya que se encuentran limitados a un área o actividad específica:

- La Ley de la Cuenca Matanza Riachuelo (Ley 26.I68 de 2006) prevé el ordenamiento ambiental de una cuenca.

- La Ley de Protección de Bosques Nativos (Ley 26.33I de 2007), el ordenamiento territorial de los bosques nativos.

- La Ley de Acuicultura (Ley 27.23I de 20I5), el ordenamiento territorial de la actividad acuícola.

- La Ley de promoción del desarrollo sustentable de las actividades turísticas de los pueblos rurales (Ley 27.324 de 2016), el ordenamiento territorial de pueblos rurales.

Una sola ley prevé un ordenamiento integral del territorio nacional: la Ley General del Ambiente (Ley 25.675 de 2002). Esta establece el ordenamiento ambiental del territorio como instrumento de la política ambiental nacional (art. 8).

En síntesis, vemos que un gran número de leyes inciden en la organización del territorio y deben ser consideradas en los procesos de planificación. Sin embargo, esta legislación no ofrece una adecuada orientación para un ordenamiento territorial integral. Solo el ordenamiento ambiental del territorio tiene este carácter, pero su regulación es escueta, agotándose en dos disposiciones, los art. 9 y io de la Ley General del Ambiente (Esain, 2008).

Conocida la conformación del marco jurídico del ordenamiento territorial vigente a nivel nacional, examinaremos si contiene normas que propician un desarrollo sostenible. 


\section{Existencia de normas que propician un desarrollo sostenible}

Para saber si el marco jurídico del ordenamiento territorial vigente a nivel nacional incorpora normas que propician un desarrollo sostenible, se cruzaron sus disposiciones con los indicadores formulados en la sección anterior (cuadro 2).

Cuadro 2. Normas del marco jurídico del ordenamiento territorial vigente a nivel nacional que verifican los indicadores de desarrollo sostenible (Argentina, 2019)

\begin{tabular}{|c|c|c|}
\hline $\begin{array}{l}\text { Dimensión de } \\
\text { análisis }\end{array}$ & $\begin{array}{l}\text { Indicador de desarrollo } \\
\text { sostenible }\end{array}$ & $\begin{array}{l}\text { Norma que verifica el indi- } \\
\text { cador }\end{array}$ \\
\hline $\begin{array}{l}\text { 1. Carácter del } \\
\text { ordenamiento } \\
\text { territorial }\end{array}$ & $\begin{array}{l}\text { a. Existencia en el marco } \\
\text { jurídico vigente del OT de } \\
\text { prescripciones relativas } \\
\text { al uso, la ocupación y la } \\
\text { transformación de todo el } \\
\text { territorio nacional. }\end{array}$ & $\begin{array}{l}\text { "El ordenamiento territorial } \\
\text { desarrollará la estructura de } \\
\text { funcionamiento global del terri- } \\
\text { torio de la Nación" (Ley 25.675, } \\
\text { 2002, art. 9). }\end{array}$ \\
\hline $\begin{array}{l}\text { 2. Diagnóstico } \\
\text { territorial }\end{array}$ & $\begin{array}{l}\text { b. Existencia en el marco } \\
\text { jurídico vigente del OT de } \\
\text { prescripciones relativas a la } \\
\text { realización de un diagnós- } \\
\text { tico territorial de carácter } \\
\text { integral, que incluya varia- } \\
\text { bles ambientales, sociales y } \\
\text { económicas. }\end{array}$ & $\begin{array}{l}\text { "(...) teniendo en cuenta los } \\
\text { aspectos políticos, físicos, so- } \\
\text { ciales, tecnológicos, culturales, } \\
\text { económicos, jurídicos y ecoló- } \\
\text { gicos de la realidad local" (Ley } \\
25.675,2002 \text {, art. 10, primer } \\
\text { párrafo). }\end{array}$ \\
\hline $\begin{array}{l}\text { 3. Modelo territorial } \\
\text { deseado }\end{array}$ & $\begin{array}{l}\text { f. Existencia en el marco } \\
\text { jurídico vigente del OT de } \\
\text { lineamientos para que los } \\
\text { objetivos operativos del OT } \\
\text { incluyan aspectos ambienta- } \\
\text { les, sociales y económicos. }\end{array}$ & $\begin{array}{l}\text { "El proceso de ordenamiento } \\
\text { ambiental (...) deberá asegurar } \\
\text { el uso ambientalmente adecua- } \\
\text { do de los recursos ambienta- } \\
\text { les" (Ley } 25.675,2002 \text {, art. } 10, \\
\text { primer párrafo). }\end{array}$ \\
\hline \multirow[t]{2}{*}{$\begin{array}{l}\text { 4. Consumo de } \\
\text { suelo }\end{array}$} & \multirow{2}{*}{$\begin{array}{l}\text { h. Existencia en el marco } \\
\text { jurídico vigente del OT de } \\
\text { delimitaciones de zonas de } \\
\text { protección, de cultivo y de } \\
\text { riesgo, y de la prohibición de } \\
\text { urbanizarlas. }\end{array}$} & $\begin{array}{l}\text { "Las categorías de conserva- } \\
\text { ción de los bosques nativos } \\
\text { son las siguientes: - Categoría } \\
\text { I (rojo): sectores de muy alto } \\
\text { valor de conservación que no } \\
\text { deben transformarse" (Ley } \\
26.331,2007 \text {, art. 9). }\end{array}$ \\
\hline & & $\begin{array}{l}\text { "En los glaciares quedan } \\
\text { prohibidas las actividades que } \\
\text { puedan afectar su condición } \\
\text { natural" (Ley 26.639, 2010, } \\
\text { art. 6). }\end{array}$ \\
\hline
\end{tabular}




\begin{tabular}{|c|c|c|}
\hline \multirow{3}{*}{$\begin{array}{l}\text { 5. Localización de } \\
\text { los usos del suelo }\end{array}$} & $\begin{array}{l}\text { k. Existencia en el marco } \\
\text { jurídico vigente del OT de } \\
\text { la prescripción de elaborar } \\
\text { la planificación territorial en } \\
\text { función del diagnóstico rea- } \\
\text { lizado, las potencialidades, } \\
\text { limitaciones, problemas y } \\
\text { riesgos del territorio y/o cri- } \\
\text { terios ambientales, sociales } \\
\text { y económicos. }\end{array}$ & $\begin{array}{l}\text { "en la localización de las } \\
\text { distintas actividades antrópicas } \\
\text { y en el desarrollo de asenta- } \\
\text { mientos humanos, se deberá } \\
\text { considerar, en forma prioritaria: } \\
\text { a) La vocación de cada zona } \\
\text { o región, en función de los } \\
\text { recursos ambientales y la sus- } \\
\text { tentabilidad social, económica } \\
\text { y ecológica" (Ley 25.675, 2002, } \\
\text { art. 10, segundo párrafo). }\end{array}$ \\
\hline & $\begin{array}{l}\text { m. Existencia en los marcos } \\
\text { jurídicos vigentes del OT de } \\
\text { mecanismos para armonizar } \\
\text { los intereses del mercado y } \\
\text { de la sociedad. }\end{array}$ & $\begin{array}{l}\text { "deberá considerar la con- } \\
\text { certación de intereses de } \\
\text { los distintos sectores de la } \\
\text { sociedad entre sí" (Ley 25.675, } \\
\text { 2002, art. 9). }\end{array}$ \\
\hline & $\begin{array}{l}\text { n. Existencia en el marco } \\
\text { jurídico vigente del OT de } \\
\text { mecanismos de coordina- } \\
\text { ción administrativa. }\end{array}$ & $\begin{array}{l}\text { "El ordenamiento ambiental } \\
\text { (...) se genera mediante la } \\
\text { coordinación interjurisdiccional } \\
\text { entre los municipios y las pro- } \\
\text { vincias, y de éstas y la ciudad } \\
\text { de Buenos Aires con la Nación, } \\
\text { a través del Consejo Federal de } \\
\text { Medio Ambiente" (Ley 25.675, } \\
\text { 2002, art. 9). }\end{array}$ \\
\hline $\begin{array}{l}\text { 8. Actividades } \\
\text { a realizar en el } \\
\text { territorio }\end{array}$ & $\begin{array}{l}\text { x. Existencia en el marco } \\
\text { jurídico vigente del OT } \\
\text { de normas que regulen } \\
\text { el comportamiento de las } \\
\text { actividades. }\end{array}$ & $\begin{array}{l}\text { "La actividad de la acuicultura } \\
\text { se llevará a cabo mediante el } \\
\text { uso de prácticas que se en- } \\
\text { cuentren enmarcadas dentro de } \\
\text { los criterios de sustentabilidad" } \\
\text { (Ley } 27.231,2016 \text {, art. 30). }\end{array}$ \\
\hline \multirow{2}{*}{$\begin{array}{l}\text { 10. Participación } \\
\text { ciudadana }\end{array}$} & $\begin{array}{l}\text { z. Existencia en el marco } \\
\text { jurídico vigente del OT de } \\
\text { mecanismos de participa- } \\
\text { ción ciudadana. }\end{array}$ & $\begin{array}{l}\text { "Créase en el ámbito de la } \\
\text { autoridad de Cuenca Matan- } \\
\text { za Riachuelo, una Comisión } \\
\text { de Participación Social, con } \\
\text { funciones consultivas (...) } \\
\text { integrada por representantes } \\
\text { de las organizaciones con inte- } \\
\text { reses en el área" (Ley 26.168, } \\
\text { 2006, art. 4). }\end{array}$ \\
\hline & $\begin{array}{l}\text { aa. Existencia en el marco } \\
\text { jurídico vigente del OT de la } \\
\text { prescripción de la partici- } \\
\text { pación ciudadana en todas } \\
\text { las fases del ordenamiento } \\
\text { territorial. }\end{array}$ & $\begin{array}{l}\text { "La participación ciudadana de- } \\
\text { berá asegurarse, principalmente } \\
\text { (...) en los planes y programas } \\
\text { de ordenamiento ambiental } \\
\text { del territorio, en particular, en } \\
\text { las etapas de planificación y } \\
\text { evaluación de resultados" (Ley } \\
25.675,2002 \text {, art. } 21 \text { ). }\end{array}$ \\
\hline
\end{tabular}

Fuente: Elaboración propia a partir de Ferrandis Martínez y Noguera Tur, 2016; Gómez Orea, 2013; Mahaim, 2014; Massiris, 2012; Pastorino, 2009; Rodríguez y Reyes, 2008; Vargas, 2000 
En el cuadro 2 se puede apreciar que el marco jurídico argentino del ordenamiento territorial verifica diez de los 27 indicadores de desarrollo sostenible. Analizando las normas pertinentes, se observa que cuatro indicadores $(\mathrm{a}, \mathrm{b}, \mathrm{k}$ y aa) se verifican integralmente. Otros seis se verifican parcialmente ( $f, h, m, n, x y z)$, en el sentido que su alcance es limitado a una sola actividad o área, o que su formulación incorpora de manera incompleta los criterios propuestos por los autores consultados para la elaboración del marco conceptual. No obstante, consideramos que estas normas merecen una mención por constituir un paso en la dirección deseada.

Estos resultados nos permiten identificar las características del marco jurídico vigente del ordenamiento territorial en cuanto a normas que propician un desarrollo sostenible (cuadro 3).

El Cuadro 3 permite apreciar que, si bien existen normas que propician un desarrollo sostenible, el marco jurídico vigente carece de numerosas normas necesarias para la consecución de tal desarrollo. 
Cuadro 3. Características del marco jurídico vigente del ordenamiento territorial a nivel nacional en cuanto a normas que propician un desarrollo sostenible (Argentina, 2018)

\begin{tabular}{|c|c|}
\hline Existen: & No existen: \\
\hline $\begin{array}{l}\text { 1. Prescripciones relativas al uso, la } \\
\text { ocupación y la transformación de todo el } \\
\text { territorio nacional. } \\
\text { 2. Prescripciones relativas a la realización } \\
\text { de un diagnóstico territorial de carácter } \\
\text { integral, que incluya variables ambienta- } \\
\text { les, sociales y económicas. } \\
\text { 3. Prescripción de elaborar la planificación } \\
\text { territorial en función del diagnóstico realiza- } \\
\text { do, las potencialidades, limitaciones, pro- } \\
\text { blemas y riesgos del territorio y/o criterios } \\
\text { ambientales, sociales y económicos. } \\
\text { 4. Mecanismos de participación ciuda- } \\
\text { dana. }\end{array}$ & \multirow[t]{2}{*}{$\begin{array}{l}\text { 1. Prescripciones relativas a la realización de } \\
\text { una evaluación ambiental del territorio. } \\
\text { 2. Prescripciones referidas a la utilización de } \\
\text { metodologías (como el análisis prospectivo } \\
\text { del territorio) para la construcción de modelos } \\
\text { territoriales. } \\
\text { 3. Objetivos estratégicos formulados en } \\
\text { términos de calidad de vida, prevención de } \\
\text { desastres, preservación de los espacios natu- } \\
\text { rales, minimización del consumo de suelo y/o } \\
\text { urbanización en el medio construido. } \\
\text { 4. Mecanismos de conciliación de los distintos } \\
\text { objetivos. } \\
\text { 5. Mecanismos de control del crecimiento urba- } \\
\text { no, tales como límites cuantitativos al consumo }\end{array}$} \\
\hline Existen de manera parcial: & \\
\hline $\begin{array}{l}\text { 5. Lineamientos para que los objetivos } \\
\text { operativos del OT incluyan aspectos } \\
\text { ambientales, sociales y económicos. } \\
\text { 6. Delimitación en los marcos jurídicos } \\
\text { vigentes del OT de zonas de protección, } \\
\text { de cultivo y de riesgo, y prohibición de } \\
\text { urbanizarlas. } \\
\text { 7. Mecanismos para armonizar los intere- } \\
\text { ses del mercado y de la sociedad. } \\
\text { 8. Mecanismos de coordinación adminis- } \\
\text { trativa. } \\
\text { 9. Normas que regulan el comportamiento } \\
\text { de las actividades. } \\
\text { 10. Prescripción de la participación ciuda- } \\
\text { dana en todas las fases del ordenamiento } \\
\text { territorial. }\end{array}$ & $\begin{array}{l}\text { 6. Procedimiento para la ponderación de los } \\
\text { intereses vinculados a la clasificación como } \\
\text { urbanizables de nuevos terrenos. } \\
\text { 7. Prescripción de cumplir la legislación am- } \\
\text { biental. } \\
\text { 8. Prescripciones orientadas a evitar la disper- } \\
\text { sión y la fragmentación urbana. } \\
\text { 9. Prescripciones que garanticen la localiza- } \\
\text { ción de los asentamientos humanos en zonas } \\
\text { seguras. } \\
\text { 10. Prescripciones relativas a la calidad ambien- } \\
\text { tal en los asentamientos humanos. } \\
\text { 11. Prescripciones relativas a la accesibilidad en } \\
\text { transporte público. } \\
\text { 12. Prescripciones relativas a la provisión de vi- } \\
\text { viendas en cercanías de los puestos de trabajo. } \\
\text { 13. Prescripciones relativas a la provisión de vi- } \\
\text { viendas para los sectores de menores recursos. } \\
\text { 14. Mecanismos para la selección de las activi- } \\
\text { dades a realizar en el territorio. } \\
\text { 15. Prescripción de coordinar las actividades } \\
\text { que son incompatibles, concurrentes, interde- } \\
\text { pendientes o complementarias. } \\
\text { 16. Prescripción de destinar para las actividades } \\
\text { productivas terrenos con acceso a infraestructura. } \\
\text { 17. Prescripción de realizar una evaluación } \\
\text { ambiental estratégica de los planes de ordena- } \\
\text { miento territorial previamente a su aprobación. }\end{array}$ \\
\hline
\end{tabular}

Fuente: elaboración propia. 
Con respecto a las leyes que contienen normas pertinentes, según el relevamiento realizado (cuadro 2), estas son:

- La Ley Cuenca Matanza Riachuelo (Ley 26.168 de 2006), que crea la Autoridad de la Cuenca Matanza Riachuelo y la faculta para planificar el ordenamiento ambiental del territorio afectado a la cuenca.

- La Ley de Protección de Bosques Nativos (Ley 26.33I de 2007), que protege estos bosques mediante el ordenamiento territorial y una zonificación de acuerdo a diferentes categorías de conservación, a las que corresponden diversas restricciones de uso.

- La Ley de Protección de Glaciares (Ley 26.639 de 20Io), que establece los presupuestos mínimos para la preservación de los glaciares y del ambiente periglacial, y prohíbe las actividades que puedan afectarlos.

- La Ley de Acuicultura (Ley 27.23I de 20I5), que tiene como objetivo propiciar el desarrollo integral y sostenible de la actividad, y proponer su ordenamiento territorial.

- La Ley General del Ambiente (Ley 25.675 de 2002), que establece al ordenamiento ambiental del territorio como instrumento de la política ambiental nacional.

Esta última ley es la que más propicia el desarrollo sostenible, ya que verifica siete indicadores $(a, b, f, k, m$ y $)$, como se puede apreciar en el cuadro 2.

En cuanto a las dimensiones de análisis, el marco jurídico vigente contempla una sola dimensión de manera integral y seis de manera parcial (al verificarse solo parte de los indicadores asociados a estas). Las restantes tres dimensiones no están contempladas (cuadro 4). 
Cuadro 4. Dimensiones de análisis contempladas en el marco jurídico del ordenamiento territorial vigente a nivel nacional (Argentina, 2019)

\begin{tabular}{l|l}
\hline Dimensiones de análisis & Resultado \\
\hline 1. Carácter del ordenamiento territorial & Integralmente contempladas \\
\hline $\begin{array}{l}\text { 2. Diagnóstico territorial } \\
\text { 10. Participación ciudadana }\end{array}$ & $\begin{array}{l}\text { Parcialmente contempladas (se verifican } \\
\text { algunos indicadores) }\end{array}$ \\
\hline $\begin{array}{l}\text { 3. Modelo territorial deseado } \\
\text { 4. Consumo de suelo }\end{array}$ & Se verifica(n) parcialmente algun(os) \\
$\begin{array}{l}\text { 5. Localización de los usos del suelo } \\
\text { 8. Actividades a realizar en el territorio }\end{array}$ & indicador(es) \\
\hline $\begin{array}{l}\text { 6. Asentamientos humanos } \\
\text { 7. Provisión de viviendas } \\
\text { 9. Evaluación de los planes de orde- } \\
\text { namiento }\end{array}$ & \\
\hline
\end{tabular}

Fuente: elaboración propia.

El Cuadro 4 muestra que la mayoría de las dimensiones de análisis no están adecuadamente contempladas en el marco jurídico vigente. La existencia de cuatro dimensiones de análisis, cuyos indicadores se verifican parcialmente $(3,4,5$ y 8$)$, parece indicar que el legislador ha percibido la relevancia de los temas en cuestión para el ordenamiento territorial. Sin embargo, no ha podido tratarlos con la amplitud necesaria para lograr un desarrollo sostenible, de acuerdo con los aportes teóricos e internacionales sobre la temática. En relación con las tres dimensiones que no están contempladas ( 6,7 y 9), es posible afirmar que el legislador no los considera temas relevantes para el ordenamiento territorial, sin perjuicio de que puedan estar regulados por otro tipo de legislación (de otro nivel de gobierno y/o con otro objeto).

Estos resultados nos permitirán evaluar la idoneidad del marco jurídico vigente del ordenamiento territorial como instrumento para un desarrollo sostenible.

\section{Idoneidad del marco jurídico vigente para un desarrollo sostenible}

Los resultados del análisis - cantidad de dimensiones de análisis contempladas, cantidad de indicadores que se verifican y de qué manera se verifican- indican que el marco jurídico argentino del ordenamiento 
territorial no propicia un desarrollo sostenible. En este sentido, no constituye un instrumento idóneo para tal desarrollo. Par convertirse en un instrumento de desarrollo sostenible, requeriría ser completado en relación con los 23 requerimientos que no satisface o satisface solo de manera parcial (evidenciados por los 23 indicadores que no se verifican o solo de manera parcial). Para completar este marco jurídico sería deseable sancionar una ley específica, que dé respuestas integrales a los problemas que plantea el ordenamiento del territorio (Pastorino, 2009).

La necesidad de contar con una ley de ordenamiento territorial no ha pasado desapercibida y se registran numerosos intentos en este sentido. Entre 2007 y 20I8, doce proyectos legislativos, con diferente alcance y visión, fueron presentados en el Congreso de la Nación (Diputados Argentina, s. f.) y todos caducaron ${ }^{6}$. Esta multiplicidad de proyectos revela la preocupación de la clase política, de los profesionales y del sector académico-científico por la temática, pero también la dificultad de aunar criterios y llegar a los consensos que requiere la sanción de una ley de esta envergadura (Fundación Cambio Democrático y Fundación Ambiente y Recursos Naturales, 20II).

Por otra parte, cabe señalar que estos doce proyectos son de ordenamiento territorial; ninguno tiene por objeto el ordenamiento ambiental del territorio. Siendo este el primer instrumento de la política ambiental, según el orden que establece la Ley General del Ambiente (art. 8), y una prioridad explícita del Consejo Federal de Medio Ambiente (2006), la carencia de propuestas en tal sentido llama la atención.

\section{Perspectivas}

Este trabajo caracterizó el marco jurídico vigente del ordenamiento territorial en Argentina en cuanto a su idoneidad como instrumento para un desarrollo sostenible. Se destacan cuatro aportes:

1. La elaboración de un marco conceptual que profundiza en la vinculación entre ordenamiento territorial y desarrollo sostenible.

6 Los proyectos más recientes son: Presupuestos Mínimos de Ordenamiento Territorial (Expediente 1094-S-2018), presentado por el Senador radical Ángel Rozas, y Presupuestos Mínimos del Ordenamiento Territorial para el Desarrollo Sustentable (Expediente 2338-D2018), presentado por Diputados del Frente para la Victoria. 
2. La formulación, a partir de este marco conceptual, de dimensiones de análisis e indicadores de desarrollo sostenible aplicables a normas jurídicas.

3. La identificación de las leyes que conforman el marco jurídico del ordenamiento territorial vigente a nivel nacional en Argentina.

4. La identificación, en este marco jurídico, de las leyes que contienen normas que propician un desarrollo sostenible.

A modo de conclusión, retomaremos brevemente los principales hallazgos.

La vinculación entre ordenamiento territorial y desarrollo sostenible ha existido desde los albores de este y ha sido estudiada por autores de diversos países y diferentes disciplinas. A partir de sus aportes, es posible definir los requisitos que el desarrollo sostenible plantea al ordenamiento territorial. En función de estos requisitos, formulamos diez dimensiones de análisis y 27 indicadores, que permitieron examinar el marco jurídico de ordenamiento territorial en relación a si propicia un desarrollo sostenible.

Este marco jurídico está conformado por 3I leyes que inciden en la organización territorial y deben ser consideradas en los procesos de ordenamiento territorial. Sin embargo, ninguna tiene por objeto el ordenamiento territorial. Esta dispersión normativa y la carencia de una norma articuladora nos permiten afirmar que esta legislación no fomenta el ordenamiento del territorio.

De estas 3I leyes, cinco contienen normas que propician un desarrollo sostenible: Ley Cuenca Matanza Riachuelo (Ley 26.I68 de 2006), Ley de Protección de Bosques Nativos (Ley 26.33I de 2007), Ley de Protección de Glaciares (Ley 26.639 de 2010), Ley de Acuicultura (Ley 27.23I de 2015) y Ley General del Ambiente (Ley 25.675 de 2002). Las disposiciones de estas leyes verifican diez de los 27 indicadores (cuatro integralmente y seis de manera parcial). Este resultado muestra que, si bien existen normas pertinentes, estas no resultan suficientes, de acuerdo con los desarrollos teóricos e internacionales sobre la temática, para que el marco jurídico vigente pueda considerarse un instrumento idóneo para un desarrollo sostenible.

Esta debilidad normativa pone de manifiesto que, a más de treinta años de la publicación del informe Brundtland, el desarrollo se piensa 
todavía principalmente en términos de crecimiento económico y sin consideración por su base territorial (Massiris, 2012) ni por las consecuencias perjudiciales que tal enfoque tiene para la sostenibilidad del desarrollo. Esta situación es probablemente producto de los poderosos intereses económicos (urbanísticos, entre otros) presentes. Así como estos intereses condicionan la política territorial (Massiris, 20I2), pueden frenar la adopción de la legislación que debería respaldar dicha política. En una sociedad periférica y dependiente como la argentina, cuyo estilo de desarrollo se basa en el extractivismo (Féliz y Migliaro, 20I8; Máttar y Perrotti, 20I4; Merchand Rojas, 20I6)7, es esperable que se dificulte la regulación del uso de los recursos naturales ${ }^{8}$.

Es importante recalcar que, entre las leyes examinadas, la que más disposiciones pertinentes contiene es la Ley General del Ambiente. Su relevancia para la consecución del desarrollo sostenible queda reflejada en las cinco dimensiones de análisis que dicha ley contempla: carácter del ordenamiento territorial, diagnóstico territorial, modelo territorial deseado, localización de los usos del suelo y participación ciudadana.

A pesar de su relevancia, esta ley no alcanza a establecer los fundamentos de una política pública compleja como lo es el ordenamiento ambiental del territorio. La implementación de este instrumento requeriría la sanción de una ley específica -una ley sectorial de presupuestos mínimos de protección ambiental (Esain, 2008) -, que desarrolle los lineamientos generales establecidos en la Ley General del Ambiente.

7 El extractivismo es "un tipo de extracción de recursos naturales, en gran volumen o alta intensidad, y que están orientados esencialmente a ser exportados como materias primas sin procesar, o con un procesamiento mínimo" (Gudynas, 2015:13). El término se aplicaba históricamente a las explotaciones mineras y petroleras, sin embargo, en años recientes, prácticas similares se han reproducido en otros sectores, tales como algunos monocultivos (por ejemplo, la soja), algunas formas de piscicultura (salmón y camarones) y el turismo de masas. En todas estas variantes, se advierten fuertes impactos territoriales y ambientales.

8 Se han observado resistencias similares en los procesos de adopción de leyes ambientales. Así, la primera Ley de Glaciares (Ley 26.418 de 2008) fue vetada por la presidenta Cristina Fernández (mediante el Decreto 1837 de 2008) y la segunda (Ley 26.639 de 2010) fue objeto de una acción por inconstitucionalidad, iniciada por una empresa minera y la provincia de San Juan (CSJ 140/2011 (47-B)/CS1 ORIGINARIO "Barrick Exploraciones Argentinas S.A. y otro c/ Estado Nacional s/ acción declarativa de inconstitucionalidad"). En cuanto a la Ley de Bosques (Ley 26.331 de 2007), el Poder Ejecutivo Nacional demoró su reglamentación (Decreto 91 de 2009) y la aprobación de la legislación provincial complementaria se extendió hasta 2015 (con la sanción de la Ley 9711 en la provincia de La Rioja), en violación del art. 6 de la Ley 26.331, que preveía un plazo de un año. 
Para que dicha ley propicie un desarrollo sostenible, sería conveniente que incorpore normas que contemplen las dimensiones de análisis utilizadas en este trabajo. Los indicadores propuestos constituyen un punto de partida en tal sentido. Con el objeto de asegurar su efectiva implementación y cumplimiento, deberá ser reglamentada y complementada por normativa provincial9.

Un marco normativo - legal y reglamentario- de estas características constituiría un valioso instrumento de desarrollo sostenible. Indudablemente, la mera sanción de una ley no garantiza que se logren los fines perseguidos: la eficacia de todo marco regulatorio (el derecho escrito) está condicionada por la manera en la que se cumplen y aplican sus normas (el derecho en acción). Los intereses económicos que paralizan la regulación de las actividades productivas tienen seguramente la capacidad de influir en el cumplimiento y aplicación de la normativa que se logre sancionar. Además, las restricciones presupuestarias afectan la disponibilidad de los recursos humanos, materiales y financieros necesarios para garantizar una adecuada gestión ambiental por parte de los organismos públicos encargados de esta (Brañes, 20oI). Aun así, contar con un respaldo legal apropiado representaría un avance sustancial para la implementación de una política de ordenamiento territorial en Argentina y la sostenibilidad de su desarrollo.

\section{Agradecimientos}

Este trabajo forma parte de una tesis doctoral en Ordenamiento Territorial y Desarrollo Sostenible, realizada bajo la dirección de María Melina Guardamagna, a quien se agradece por la orientación brindada en la formulación de los indicadores.

9 Tal como lo prevé el art. 41, tercer párrafo, de la Constitución Nacional: "Corresponde a la Nación dictar las normas que contengan los presupuestos mínimos de protección, y a las provincias, las necesarias para complementarlas (....." 


\section{Referencias bibliográficas}

Alburquerque, F. y Pérez, S. (2013). El desarrollo territorial: enfoque, contenido y políticas, Revista Iberoamericana de Gobierno Local-RIGL, $\mathrm{N}^{\circ}$, pp. I-24.

Asamblea General de las Naciones Unidas (2015). Transformar nuestro mundo: la Agenda 2030 para el Desarrollo Sostenible [En línea] Recuperado de https:// undocs.org/es/A/RES/70/I (I4 de octubre de 20I9)

Bermejo Gómez de Segura, R. (2014). Del desarrollo Sostenible según Brundtland a la sostenibilidad como biomímesis, San Sebastián: Hegoa [En línea] Recuperado de http://publicaciones.hegoa.ehu.es/publications/3I5 (I4 de octubre de 20I9)

Brañes, R. (200I). Informe sobre el desarrollo del derecho ambiental latinoamericano. Su aplicación después de diez años de la Conferencia de las Naciones Unidas sobre el Medio Ambiente y el Desarrollo, México, D.F.: Programa de las Naciones Unidas para el Medio Ambiente.

Burgess R. (2003). Ciudad y sostenibilidad: desarrollo urbano sostenible, en M. Balbo, R. Jordán y D. Simioni (comp.), La ciudad inclusiva (pp. 193213), Santiago de Chile: Comisión Económica para América Latina y el Caribe [En línea] Recuperado de https://repositorio.cepal.org/bitstream/ handle/II362/27824/S2003002_es.pdf?sequence $=\mathrm{I} \&$ risAllowed $=y$ (I4 de octubre de 20I9)

Comisión Mundial sobre el Medio Ambiente y el Desarrollo (1987). Informe Nuestro Futuro Común. Nueva York: Naciones Unidas [En línea] Recuperado de http://www.un.org/es/comun/docs/?symbol=A/42/427 (I4 de octubre de 20I9)

Consejo Federal de Medio Ambiente (2006). Documento final sobre la fijación de prioridades ambientales del COFEMA [En línea] Recuperado de http:// cofema.ambiente.gob.ar/archivos/web/COFEMA/File/fijacion prioridades cofema.pdf (I3 de octubre de 20I9)

Declaración de Johannesburgo sobre el Desarrollo Sostenible (2002). [En línea] Recuperado de https://www.un.org/spanish/esa/sustdev/WSSDsp PD.htm (I4 de octubre de 20I9)

Declaración de Río sobre Medio Ambiente y Desarrollo (1992). [En línea] Recuperado de https://www.un.org/spanish/esa/sustdev/agenda2I/ riodeclaration.htm (I4 de octubre de 2019)

Diputados Argentina (s. f.). Buscador de proyectos [En línea] Recuperado de https://www.hcdn.gob.ar/proyectos/index.html 
Elorrieta, B., Olcina, J. y Sánchez, D. (2016). La sostenibilidad en la planificación territorial de escala regional, Cuadernos Geográficos, Vol. 55 $\left(\mathrm{N}^{\circ} \mathrm{I}\right)$, pp. I49-I75.

Elizalde, A. (1992). Desarrollo y Sustentabilidad: límites y potencialidades (Una mirada desde la perspectiva del Sur), en Documentación Social. Revista de Estudios Sociales y de Sociología Aplicada, No 89.

Elizalde, A. (2009). ¿Qué desarrollo puede llamarse sostenible en el siglo Xxı? La cuestión de los límites y las necesidades humanas, Revista de educación, No extraordinario ańo 2009. Educar para el desarrollo sostenible, pp. 53-75.

Esain, J. A. (2008). Competencias Ambientales, Buenos Aires: Abeledo Perrot. (2012). La protección de la flora y los bosques nativos en el derecho ambiental argentino, Cuaderno de Derecho Ambiental, III Bosques, pp. 79-I33.

Féliz, M. y Migliaro, A. I. (20r8). Superexplotación de la naturaleza y el trabajo en sociedades extractivas. Capitalismo y patriarcado en el neodesarrollismo en la Argentina, Ambiente \& Educação, Vol. 23 (3), pp. 20I-229.

Ferrandis Martínez, A. y Noguera Tur, J. (2016). Planeamiento territorial sostenible: un reto para el futuro de nuestras sociedades; criterios aplicados, Cadernos Metrópole, Vol. I8 (37), pp. 743-763.

\section{Fundación Cambio Democrático y Fundación Ambiente y Recursos} Naturales (20II). El Ordenamiento Ambiental del Territorio como herramienta para la prevención y transformación democrática de conflictos socio-ambientales. Lineamientos básicos y recomendaciones para el desarrollo de una politica nacional. Volumen 2, Buenos Aires: autores [En línea] Recuperado de http://45.79.210.6/ wp-content/uploads/20I7/o4/El-Ordenamiento-Ambiental-del-Territorio\%E2\%80\%93-Volumen-2.pdf (I4 de octubre de 2019)

García Collazo, M. A. y Panizza, A. (2014). Aspectos normativos vinculados al ordenamiento territorial en argentina, en J. M. Paruelo, E. G. Jobbágy, P. Laterra, H. Dieguez, M. A. García Collazo y A. Panizza (Ed.), Ordenamiento territorial rural: conceptos, métodos y experiencias, Buenos Aires: Universidad de Buenos Aires, Ministerio de Agricultura, Ganadería y Pesca y Organización de las Naciones Unidas para la Alimentación y la Agricultura [En línea] Recuperado de http://www.fao.org/3/a-i4I95s.pdf (I4 de octubre de 20I9)

Gómez Orea, D. y Gómez Villarino, A. (2013). Ordenación territorial ( $3^{\mathrm{a}} \mathrm{ed}$.), Madrid: Mundi-Prensa Libros.

Gudińo, M. E. (2009). Instrumentos para la gestión del territorio. Ley de Ordenamiento Territorial y sistemas de información geográfica, en B. G. Díaz y P. Calviño (Compiladores), Jornadas Regionales de Información 
Geográfica y Ordenamiento Territorial, pp. 22-47 [En línea] Recuperado de http://www.sitsantacruz.gob.ar/info geografica/archivos/oroz/libros/ Instrumentos.pdf (I4 de octubre de 20I9)

(2016). El Ordenamiento Territorial como política de Estado, Perspectiva Geográfica, Vol. 20 (I), pp. II-36.

Gudynas, E. (20I0). Desarrollo sostenible: una guía básica de conceptos y tendencias hacia otra economía, Otra Economía, Vol. IV ( ${ }^{\circ}$ 6), pp. 43-66. (20II). Debates sobre el desarrollo y sus alternativas en América Latina: Una breve guía heterodoxa, en M. Lang y D. Mokrani (Ed.) Grupo Permanente de Trabajo sobre Alternativas al Desarrollo, Más allá del desarrollo (pp. 2I-53), Quito, Ecuador: Fundación Rosa Luxemburg / Abya Yala [En línea] recuperado de http://www.gudynas.com/publicaciones/capitulos/ GudynasDesarrolloGuiaHeterodoxaFRLQuitoII.pdf (20 de mayo de 2019) (2015). Extractivismos. Ecología, economía y politica de un modo de entender el desarrollo y la Naturaleza, Cochabamba, Bolivia: Centro de Documentación e Información Bolivia [En línea] Recuperado de http://gudynas.com/wpcontent/uploads/GudynasExtractivismosEcologiaPoliticaBorsAnuncio.pdf (20 de mayo de 2019)

Guimaráes R. (1994). Desarrollo sustentable: ¿Propuesta alternativa o retórica neoliberal?, Temas de Ciencia y Tecnología, No 8, pp. 3I-47. (2002). La ética de la sustentabilidad y la formulación de políticas de desarrollo, en Ecología Politicas, Naturaleza, Sociedad y Utopia, Buenos Aires: CLACSO [En línea] Recuperado de http://www.biblioteca.clacso.edu.ar/ar/ libros/ecologia/guimaraes.pdf (I4 de octubre de 20I9)

Leff, E. (2008). Decrecimiento o desconstrucción de la economía: Hacia un mundo sustentable, Polis, Vol. 7 (2I), pp. 8I-90.

Lélé, S. M. (199I). Sustainable Development: A Critical Review, World Development, Vol. I9 (6), pp. 607-621.

López Alfonsín, M. (2012). Derecho ambiental, Buenos Aires: Editorial Astrea.

Lorenzetti, R. L. (2008). Teoría del derecho ambiental, Buenos Aires: La Ley.

Mahaim, R. (2014). Le principe de durabilité et l'aménagement du territoire. Le mitage du territoire à l'épreuve du droit: utilisation mesurée du sol, urbanisation et dimensionnement des zones à bâtir [El principio de sostenibilidad y el ordenamiento territorial. La fragmentación del territorio y la prueba del derecho: uso mesurado del suelo, urbanización y dimensionamiento de las zonas edificables], Zúrich: Schulthess.

Massiris Cabeza, A. (2005). Fundamentos conceptuales y metodológicos del ordenamiento territorial, Tunja: Grupo Imprenta y Publicaciones Universidad 
Pedagógica y Tecnológica de Colombia [En línea] Recuperado de https:// www.massiris.com/20I2/og/libro-fundamentos-conceptuales-y.html (I4 de octubre de 2019) - (2012). Gestión territorial y desarrollo: hacia una política de desarrollo territorial sostenible en América Latina, Tunja: Grupo Imprenta y Publicaciones Universidad Pedagógica y Tecnológica de Colombia. (2013). "Políticas de ordenamiento territorial en América Latina: Examen comparado", Ponencia presentada ante la Comunidad Andina, Lima [En línea] Recuperado de http://app.sni.gob.ec/sni-link/sni/PORTAL SNI/ data sigad plus/sigadplusresolucion/I768134580003 Modulo\%20I 07-0420I6_I2-50-50.pdf (I4 de octubre de 20I9)

Máttar, J. J. y Perrotti, D. E. (20I4). La planificación como instrumento de desarrollo con igualdad en América Latina y el Caribe. Santiago de Chile: CEPAL [En línea] Recuperado de https://www.researchgate.net/ publication/328314404 La planificacion como instrumento de desarrollo con igualdad en America Latina y el Caribe ( 26 de mayo de 2019)

Merchand Rojas, M. A. (2016). Neoextractivimo y conflictos ambientales en América Latina, Espiral, Vol XXIII (66), pp. 155-192.

Montes Lira, P. F. (200I). El ordenamiento territorial como opción de politicas urbanas y regionales en América Latina y el Caribe, Santiago de Chile: CEPAL [En línea] Recuperado de https://repositorio.cepal.org/handle/II362/5739 (I4 de octubre de 2019)

Norgaard, R. B. (1994). Development betrayed: the end of progress and a coevolutionary revisioning of the future, Londres y Nueva York: Routledge.

Organización de las Naciones Unidas (1992). Integración del medio ambiente y el desarrollo en la adopción de decisiones, en Programa $2 I$ [En línea] Recuperado de https://www.un.org/spanish/esa/sustdev/agenda2I/ agenda2ispchapter8.htm (I4 de octubre de 20I9)

Pastorino, L. F. (2009). El Ordenamiento Ambiental Territorial, McGill Int'l J. Sust. Dev. L. y Pol'y, Vol. 5 (2), pp. 227-250 [En línea] Recuperado de https:// www.mcgill.ca/mjsdl/files $/ \mathrm{mjsdl} / 52$ 4 pastorino.pdf (I4 de octubre de 2019)

Psathakis, J. et al. (2010). Una aproximación al Ordenamiento Ambiental del Territorio como herramienta para la prevención y trasformación democrática de conflictos socio-ambientales - Volumen I, Buenos Aires; Fundación Cambio Democrático y Fundación Ambiente y Recursos Naturales [En línea] Recuperado de http://45.79.210.6/wp-content/uploads/20I7/04/ EL-ORDENAMIENTO-AMBIENTAL-DEL-TERRITORIO.pdf

(I4 de octubre de 20I9) 
Riechmann, J. (2005). Sostenibilidad: algunas reflexiones básicas [En línea] Recuperado de https:/www.upf.edu/materials/polietica/ pdf/ sossostenibilidadreflexiones.pdf (I4 de octubre de 2019) (2012). Sobre sustentabilidad y desarrollo sostenible [En línea]

Recuperado de http://www.seipaz.org/documentos/o6Jorge\%20 Riechmann\%20SOBRE\%20SUSTENTABILIDAD\%20Y\%20 DESARROLLO\%20SOSTENIBLE.pdf (I4 de octubre de 2019)

Rodríguez, C. A. (2012). El derecho humano al ambiente sano: los derechos ambientales desde la perspectiva de los derechos humanos, Santa Fe: RubinzalCulzoni.

Rodríguez, C. y Reyes, S. (2008). Propuesta metodológica para la elaboración de un plan de ordenamiento te ritorial sustentable, Proyección, Vol. I (4).

Salas Bourgoin, M. A. y Sulbarán Zambrano, E. (20II). Modificación de la Ley Orgánica para la Ordenación del Territorio en Venezuela: revisión de un proceso de Io años sin perspectivas de cristalización, Provincia, $\mathrm{N}^{\circ}$ 26, pp. 33-66.

Subirats, J., Knoepfel, P., Larrue, C., y Varone, F. (2008). Análisis y gestión de politicas públicas, Barcelona: Ariel.

Vargas, J. E. (2002). Politicas públicas para la reducción de la vulnerabilidad frente a los desastres naturales y socio-naturales, Santiago de Chile: CEPAL/United Nations Publications [En línea] Recuperado de http://repositorio.cepal.org/ bitstream/handle/II362/5749/I/S20026I2 es.pdf (I4 de octubre de 2019)

Walsh, J. R. (2009). El Ordenamiento Territorial como herramienta para el desarrollo sustentable, Actas del III Encuentro del FAOS (Foro de la Abogacía organizada Sudamericana), Comisión II: Desarrollo sustentable en América Latina, pp. 35-4I, San Isidro. 